\title{
Design of Bed Structure Aiming the Control of Void Structure Formed in the Sinter Cake
}

\author{
Eiki KASAI, Sergey KOMAROV, Koichi NUSHIRO') and Masanori NAKANO²) \\ Institute of Multidisciplinary Research for Advanced Materials, Tohoku University, 2-1-1, Katahira, Aoba-ku, Sendai $980-8577$ \\ Japan. $\quad$ 1) Steel Research Laboratory, JFE Steel Corporation, Kawasaki-cho, Chuo-ku, Chiba 260-0835 Japan. \\ 2) Environment \& Process Technology Center, Nippon Steel Corporation, Shintomi, Futtsu, Chiba 293-8511 Japan.
}

(Received on September 1, 2004; accepted on October 27, 2004)

\begin{abstract}
Design of bed structure is a promising approach to maintain/increase the productivity of sinter under the condition of increasing use of iron ores having high combined water content. In this paper, a new process image, MEBIOS, is illustrated and further "in situ" observation of the change in the void structure of the sintering bed by using X-ray CTS and a numerical simulation have been conducted in order to preliminary evaluate the possibility of this proposal.

X-ray CTS observation suggests that the existence of pellets of $15 \mathrm{~mm}$ in size does not significantly affect the formation of macroscopic void network in the sintering bed and not lead to inhomogeneous sintering. A series of the laboratory-scale of sinter pot experiment was also carried out to obtain parameters for the simulation. The gas flow near the pellet surface and the differences in the temperature profiles among the pellet center and surface were simulated by using the numerical model although further studies are necessary, e.g., on the considering ways of structural changes of void in the sintering bed, reduction and oxidation reactions and a mesh generation method properly representing the contraction of bed height.
\end{abstract}

KEY WORDS: iron ore sintering; bed structure; sinter cake; void network; aging bed; induction bed; X-ray CTS; numerical simulation.

\section{Introduction}

Recent increase in steel production has led to difficulty for ensuring of quality iron ores like high-grade Brockman deposit and therefore the flexible use of lower grade ores have become an important issue. The proportion of iron ores containing a large amount of combined water, e.g., pisolite and marramamba, has been increased year by year in the raw materials of sinter in Japan. It is expected that this trends will be kept in the near future.

It should be pointed out that a partition design of raw materials and an aggressive control of the bed structure are keys to maintain/increase the productivity of sinter considering the property of iron ores with high combined water content. Some technologies have been previously proposed, such as the separation/segregation of raw materials and the selective granulation. Specifically, their concept is an appropriate arrangement of two different types of beds, i.e., "induction bed", which induces a proper permeation structure (void network), and "aging bed", in which the induration of the fine materials moderately occurs without the formation of excessive melt. In the former bed, sintering proceeds by the coke combustion and convective heat transfer from the gas through the bed similarly to a normal sintering mechanism. In the latter bed, it proceeds mainly by the heat supply from the inducing bed and a convective heat transfer inside the bed similarly to the normal pellet induration process. To maximize the merit led by this method, the total design of the bed structure of raw material and the preparation of a dense aging bed are essential to realize an ideal void network in the sintering bed.

In this paper, a process image of the above proposal is illustrated as a technological countermeasure to the use of a large amount of ores having high combined water content. Further, "in situ" observation of the change in the void structure of the sintering bed by using X-ray CTS and a numerical simulation have been conducted to obtain the necessary information for optimizing the bed arrangement. The recent results of this study are also described.

\section{Principle for the Structural Design of Sintering Bed}

The initial structure of sintering bed can be regarded as a packed bed of granules, which are the product of granulation of raw materials with water. In the sintering process, melt forms at the part where relatively fine iron ores and limestone are segregated and the amount of melt increases with increase in temperature. Melt bridges unmelted particles and sinter cake forms as a bulk solid body, which includes void network (Fig. 1). This structural change seems to be a continuous phenomenon associated with a consistent increase in the apparent particle size, in other words, decrease in the specific surface area or increase in the void size. The final structure is determined when the temperature is decreased and the fluidity of whole bed is lowered because of solidification. 


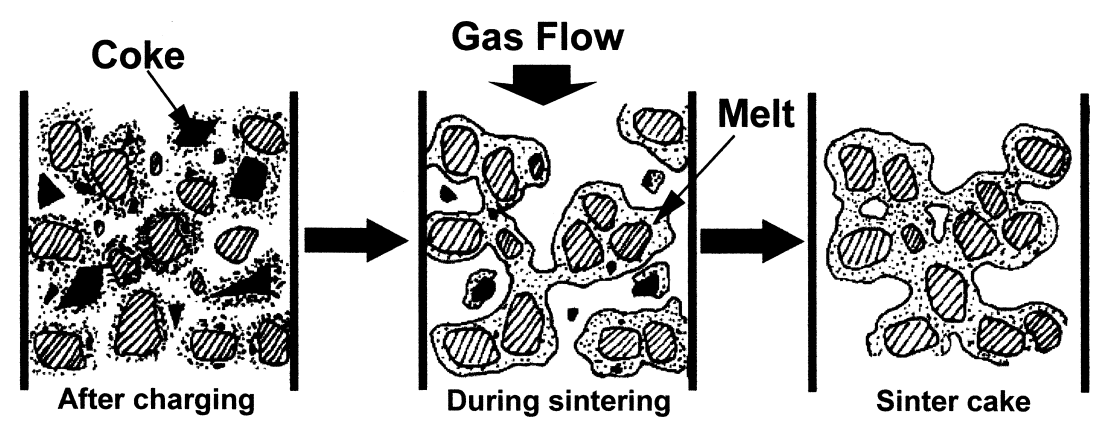

Fig. 1. Structural change from the raw material bed to the cake during sintering.

From the viewpoint of the structural change of packed bed, it can be also characterized as an increase in mean cluster size of granules bridged by melt. In this sense, the average cluster size is a parameter (the characteristic size) representing the extent of agglomeration of the sintering bed. On the other hand, it is also characterized as the coalescence of voids and pores. Hence, when this process is promoted, e.g., by the increase in the bed temperature, average sizes of both the cluster and void increase. In the case that the bed temperature excessively increases, however, a large amount of melt flows and blocks the permeation paths and, as a result, unsintered part is appeared underneath. Therefore, it is interesting to know the maximum cluster size and the corresponding sintering condition, which does not lead to such an undesired phenomenon. At the normal sintering condition, the structure may be settled in the course of increasing in the cluster size that results in a periodical mosaic structure. ${ }^{1}$ The cluster size increases with melt fraction and apparent fluidity; for instance, admixing ratio of coke to the raw mixture gives a significant effect (Fig. 2).

Iron ores with high combined water content have goethite as the major component and porosity of the ores after calcinations are large. Hence, their assimilability with melt formed during sintering is considerably high. At the condition of limited concentration of $\mathrm{CaO}$, this property leads to the difficulties associated with insufficient fluidity of the formed melt at low temperature but, on the contrary, the whole cluster rapidly melts down at higher temperature. These are the reasons of a decrease in the productivity and an extension of sintering time when a large amount of ores with high combined water content is used.

To reduce the influence of such high assimilability, preheating treatment methods such as the self-densification ${ }^{2}$ and the pisolite ore heath ${ }^{3}$ methods have been proposed. However, typical marramamba ore consists of mainly fine particles. Therefore the above methods will not be effective and homogeneous mixing of this kind of ores will promote unnecessary assimilation.

One of the authors has presented several examples of the structural design of sintering bed. $\left.{ }^{4}\right)$ However, considering the difficulties in pretreatment and charging process of the aging bed, the structure illustrated in Fig. 3 seems to be rather practical; pre-granulated dense pellets (aging bed) are properly arranged in the induction bed, which can form an ideal void network under the normal sintering condition. In this case, marramamba is used as the main ore for the pellet preparation and its induration is expected by the heat

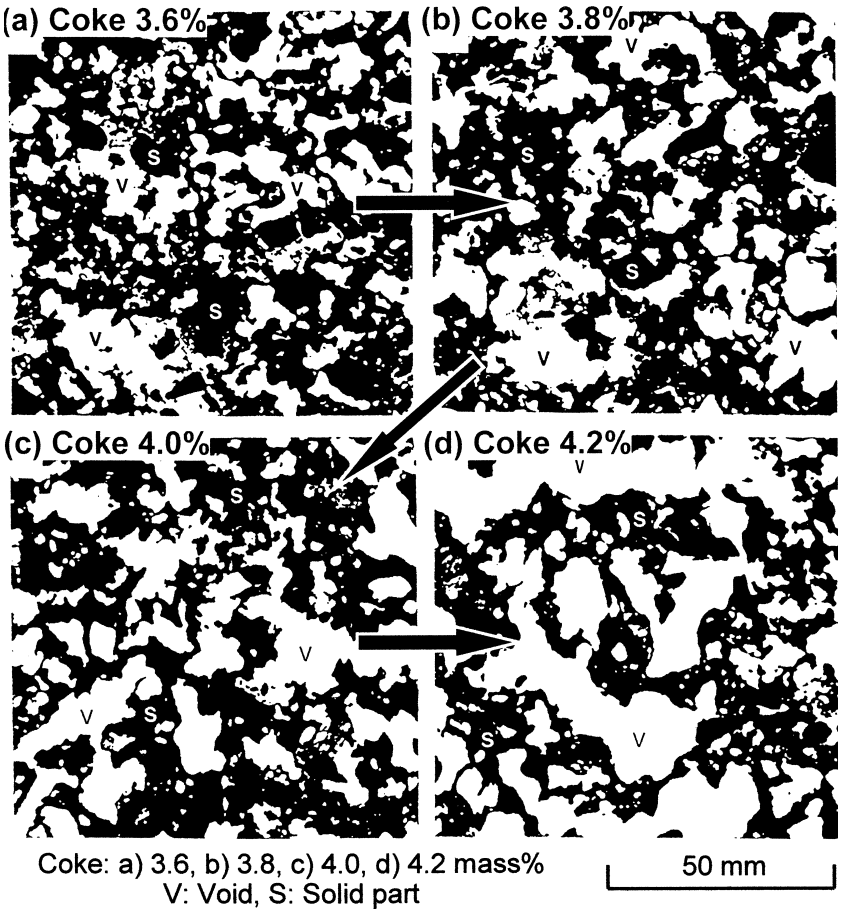

Fig. 2. Sinter cake structure prepared by varying coke rate.

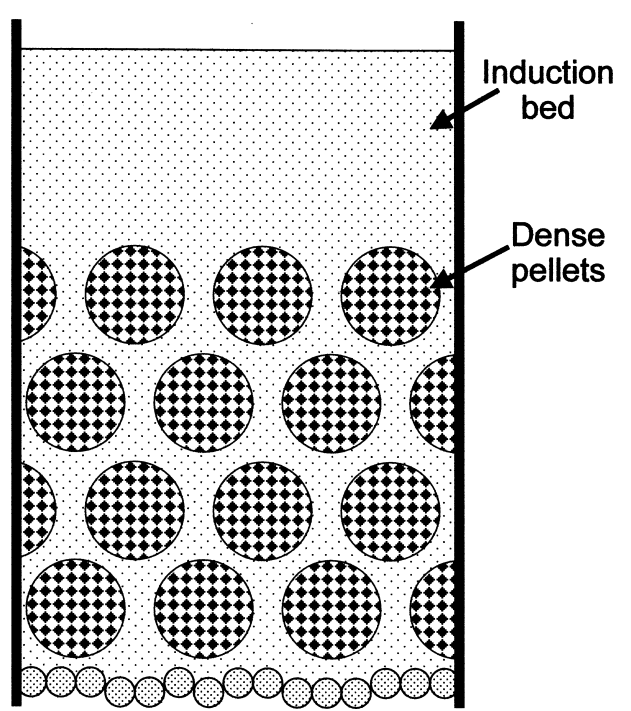

Fig. 3. An image of the design of bed structure of raw materials.

supply from the induction bed and gas through the bed during sintering. At the same time, the role of a constituent material maintaining proper void structure is expected for the pellets by the suppression of significant deformation at 
high temperatures. Especially, design/control of the position and size of voids formed in the sinter cake is an important technology, which leads to the control of size distribution of the sinter product. The "Research Project for Porous Mesomosaic Texture Sinter" of ISIJ has proposed this process, namely MEBIOS (Mosaic EmBedding Iron Ore Sintering) method.

\section{In Situ Observation of the Change in the Void Structure Using X-ray CTS}

One of the important parameters in the sintering process applying to the bed structure design like shown in Fig. 3 is appropriate range of the pellet (aging bed) size. To avoid inhomogeneous sintering, it is necessary that the gas sufficiently flows under the pellets and therefore a certain upper limit of the pellet size may exist. Further, considering the induration of the pellets, another size limit can be expected form a viewpoint of heat transfer rate inside the pellet. In this study, in situ observation of the changes in the void structure has been made using X-ray CTS, in order to examine the upper limit of pellet size provided by gas flow. To evaluate its heat transfer-based limit, it is desirable to per- form a numerical simulation, mentioned later, by quantitatively understanding the various endo- and exo-thermic reactions and densification phenomena.

In the previous study, ${ }^{5)}$ using X-ray CTS, a large size of void was formed just under the disk, $30 \mathrm{~mm}$ in diameter and $3 \mathrm{~mm}$ in thickness, made of alumina fiber during sintering (Fig. 4). It is because the sintering bed near the edge of the disk moves downward and therefore the gas flow under the disk is ensured. It suggests that the existence of impermeable objects of such size will not significantly affect the formation of macroscopic void network and also not be serious cause of inhomogeneous sintering.

In this study, model sintering experiments were conducted by using laboratory scale sinter pot $(100 \mathrm{~mm}$ in inside diameter, $100 \mathrm{~mm}$ in hieght) and X-ray CTS. In this series of the sintering experiment, one pre-granulated pellet was placed at the center of the sintering bed. Figures 5(a) and 5(b) show the changes in the cross-sectional image of the sintering bed for the two cases in which the pre-granulated pellets of $15 \mathrm{~mm}$ in diameter, by "marramamba ore+fine coke (4 mass\%)" and "marramamba ore only", respectively, were placed in the center of the sintering bed. The preparation method of the mixture (induction bed) is similar to that

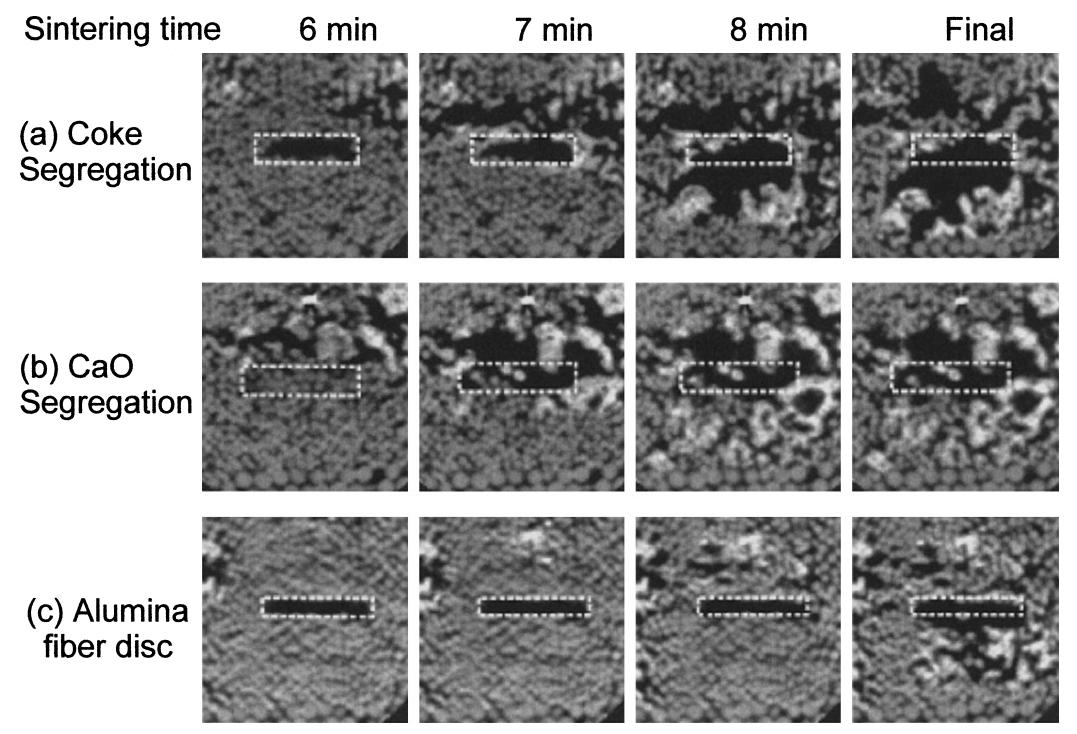

Fig. 4. Changes in the bed structure for various segregation conditions of raw materials $(70 \times 70 \mathrm{~mm})$.

(a)
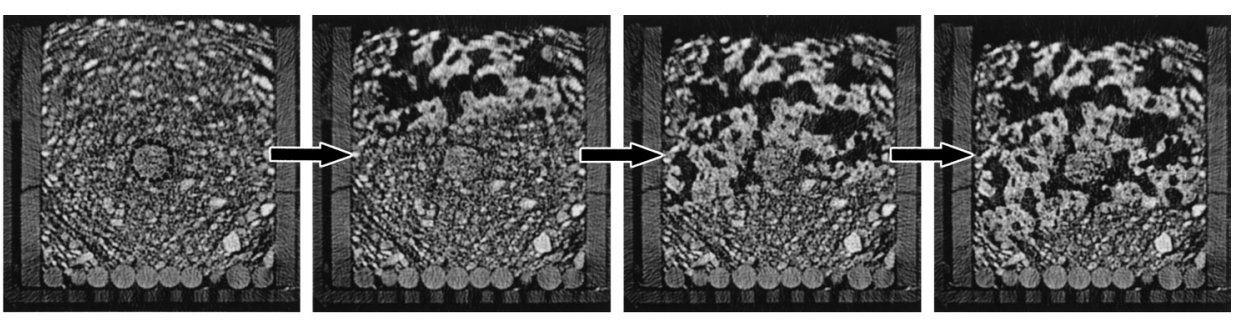

(b)
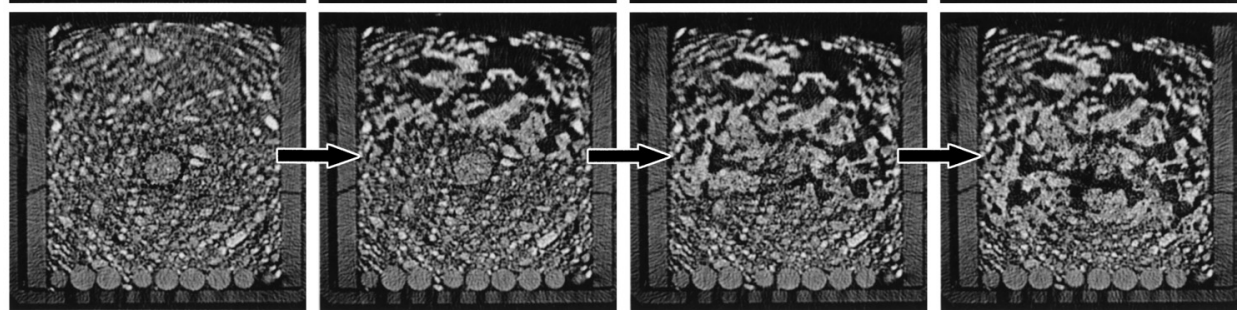

Fig. 5. Structural changes of the bed around the pellet of $15 \mathrm{~mm} \varphi$ " $(120 \times 120 \mathrm{~mm})$. Pellet was consisted of (a) marramamba ore + coke $(4$ mass $\%)$ and (b) marramamba ore only. 
for the temperature measurement described later.

Formation of the gaps between the pellet surface and the surrounding bed were observed during sintering in both the cases, especially larger gaps tended to form just under the pellet. This is the similar phenomenon to the formation process of large void observed when the above alumina fiber disk was placed in the bed shown in Fig. 4. A wall effect in the vicinity of the pellet surface seems to elicit such phenomenon and can be one of the essential process principles for high speed sintering. In addition, the sintering of the pellet seemed to progress more when fine coke was mixed in the pellet.

The above results suggest that the charge of the pre-granulated pellets, up to $15 \mathrm{~mm}$ size, in the sintering bed does not lead to significant inhomogeneous sintering. Further, maintenance of macroscopic permeability of the bed and control of void network structure will be realized by the arrangement of the pellets in the bed. The prevention of collapse and excess deformation of the pellets during sintering will also be made by the understanding of various process factors, e.g., mixing ratio of carbonaceous materials such as fine coke and dusts, $\mathrm{CaO}$ concentration, apparent density of pellet, thermal cracking property of ores.

\section{Temperature Measurements of the Sintering Bed and Pellet, and the Numerical Simulation}

In this study, a numerical simulation model is being developed by means of a general code of thermo-fluid dynamics in order to examine effectively the influences of the pellet shape and size, relation between the temperatures of induction bed and the inside of pellets, proper arrangement of pellets in the bed and so forth. The model is based on a commercial CFD software. At the same time, sintering experiments have been conducted by using a laboratory-scale sinter pot with $70 \mathrm{~mm}$ inside diameter and $400 \mathrm{~mm}$ bed height, in order to obtain data for the parameter-fitting, which is necessary for the development of the simulation model. In the sintering experiments, a pellet prepared from hematite reagent powder or ground pisolitic ore and bentnite powder used as binder was placed in the sintering bed (Fig. 6). The pellets $(5,10$ or $15 \mathrm{~mm}$ in size) were prepared by the granulator using a rotating tire with spraying water. The water content of the pellets was about 9 mass $\%$ for hematite and $8 \%$ for pisolitic ore. The used mixture (induction bed) was similar to a normal raw material mixture. It was prepared by using marramamba ore 30.3 , hematite ore 15.2, pisolitic ores 27.2, limestone 12.1 and return ore 15.2 (mass\%). Then, 5 or 6 mass $\%$ coke was added and it was mixed for 7 min using a drum-type granulator with spraying water. The water content after granulation was around 5 mass \%.

Figure 7 shows an example of changes in temperature of the surface and center part of the pellet, $\mathrm{TC}_{\mathrm{O}}$ and $\mathrm{TC}_{\mathrm{C}}$, respectively, with time. A certain time delay is observed in temperature increase for the center part of the pellet compared to the surface. Further, the maximum temperature of the center part tends to be lower than the surface. Figure 8 shows the effect of pellet size on the deference between $\mathrm{TC}_{\mathrm{O}}$ and $\mathrm{TC}_{\mathrm{C}}$. There is a tendency for lowering $\mathrm{TC}_{\mathrm{C}}$ against $\mathrm{TC}_{\mathrm{O}}$, although a large fluctuation is found in the data. In ad-

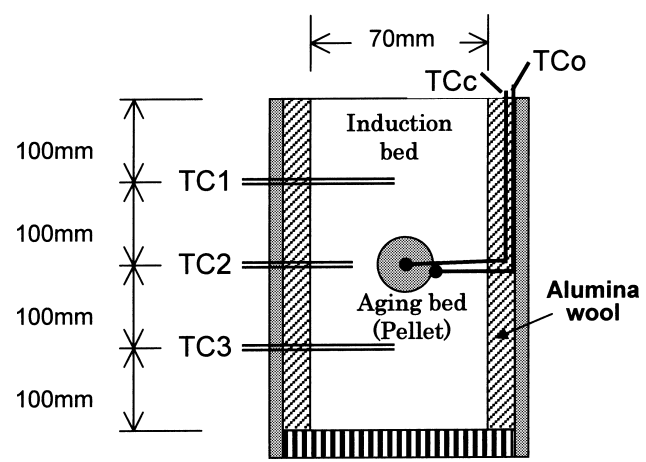

Fig. 6. Arrangement of small sinter-pot test.

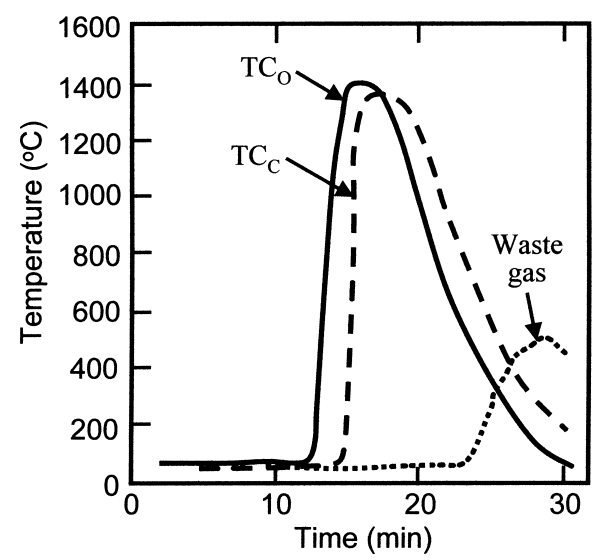

Fig. 7. Typical temperature profiles of $\mathrm{TC}_{\mathrm{O}}, \mathrm{TC}_{\mathrm{C}}$ and waste gas temperature. (Case of $10 \mathrm{~mm}$ pellet (hematite reagent))

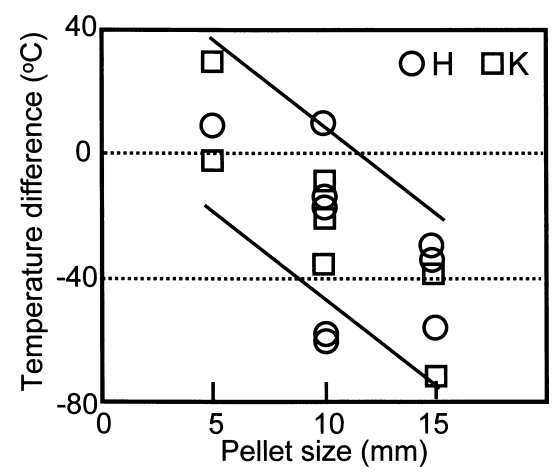

Fig. 8. Relation between size of pellet and the temperature difference of the center to the surface. ( $\mathrm{H}$ : prepared by hematite reagent, $\mathrm{K}$ : prepared by pisolitic ore)

dition, only a single pre-granulated pellet has been used in the present experiment. This is because the purpose of the experiment is to obtain the proper set of process parameters necessary for the development of a simulation model.

At the beginning of the numerical study, a test code was developed to investigate the gas flow, heat transfer and major reactions in general. Figure 9 presents the code computational domain and its meshing. The domain concerns an axi-symmetrical two-dimensional area with a spherical pellet at the central part and induction bed surrounding it.

In the simulation, momentum, heat and mass transfers are computed considering the major reactions such as water evaporation, limestone decomposition, coke combustion, calcium-ferrite formation, melt-formation and solidification. For the calculation of gas flow through the sintering 
bed, Ergun's equation, which is the empirical relationship for pressure drop in a packed bed, was incorporated into the equations of momentum transfer. The representative values of void fraction and average particle diameter are assigned to the induction bed and the pre-granulated pellet (the aging bed), respectively. In addition, the above-mentioned wall effect on the gas flow near the surface of the pellets can not

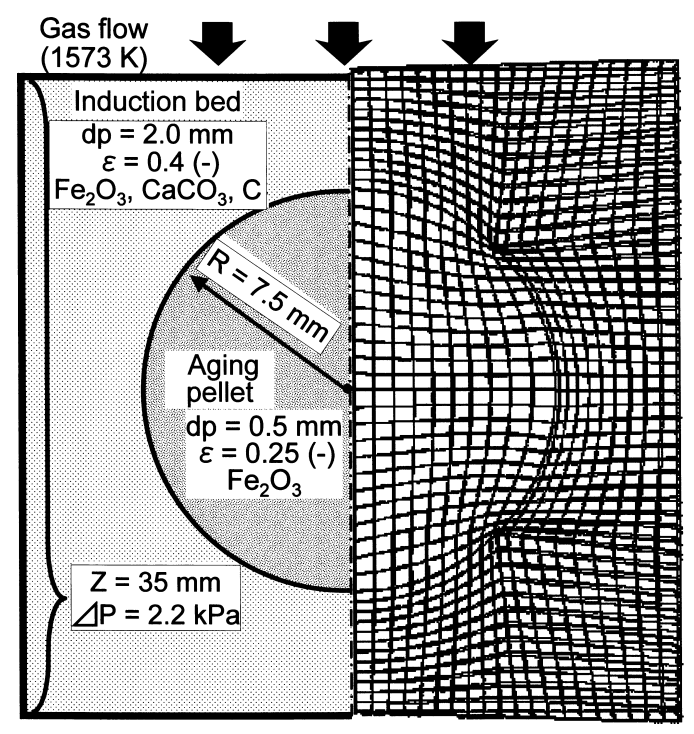

Fig. 9. An example of the simulation region and prepared mesh.

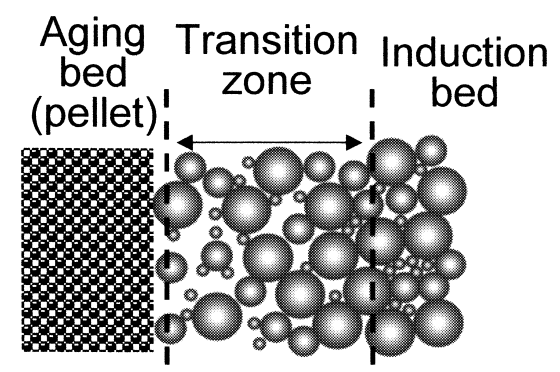

Fig. 10. Continual change of void fraction from the pellet surface toward the induction bed. be negligible when relatively large pellets are used (Fig. 10). If the wall effect is significant, gas will flow easier in the vicinity of the pellet and heat the pellet surface. In the present simulation model, the wall effect is considered by a continuously increase in the values of void fraction given to the corresponding meshes from bulk induction bed toward the surface of the pellet.

Examples of the simulation results are shown in Figs. 11 and 12. Figure 11 gives the changes in the distributions of heat generation rate and solid temperature with progress of sintering in the case that the pre-granulated pellet with $15 \mathrm{~mm}$ in size was placed at the center of the sintering bed ( $200 \mathrm{~mm}$ from the top of the bed). It represents the remarkable phenomena such as detour flow of gas around of the pellet and promotion of sintering due to an increase in gas flow rate at the pellet surface. Figure 12 shows the changes in temperatures of the pellet surface, $\mathrm{TC}_{\mathrm{O}}$, and center, $\mathrm{TC}_{\mathrm{C}}$, with time in the case that the pellets with the size 5, 10 and $15 \mathrm{~mm}$ were placed at the center of the sintering bed. For the case of $5 \mathrm{~mm}$ pellet, no significant difference between both temperatures is observed. However, certain time delays are observed in the temperature rise at the pellet center compared to that at the surface in the cases of 10 and $15 \mathrm{~mm}$ pellets. In addition, the extent of the delay becomes significant with an increase in the pellet size. However, the differences in the both maximum temperatures are extremely small and this is different from the result of the sinter pot experiment shown in Fig. 8. It may be caused by some error in the estimation of apparent thermal conductivity inside the pellet. In the present model, it is estimated by referring the calculation method ${ }^{6)}$ of thermal diffusivity applied to a porous hematite, but further examination is necessary on its validity.

The simulation model will be further developed aiming at apply to the design of the sintering bed, which ensures a sufficient heat supply to the pellet. For this purpose, a number of subjects are still remained, e.g., considering ways of structural changes of void in the sintering bed, reduction and oxidation reactions, which becomes significant on

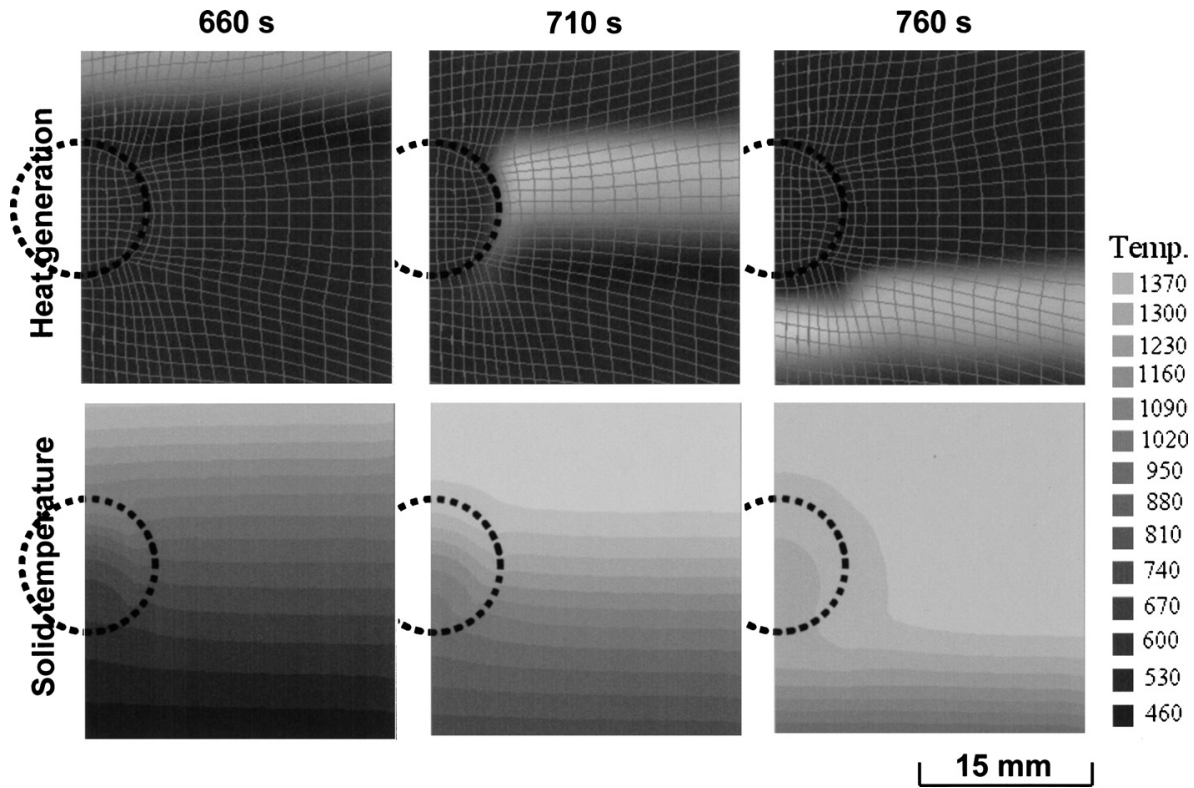

Fig. 11. Example of computed distributions of heat generation rate and solid temperature in the sintering bed with the pellet of $15 \mathrm{~mm}$ at 660,710 and $760 \mathrm{~s}$. 

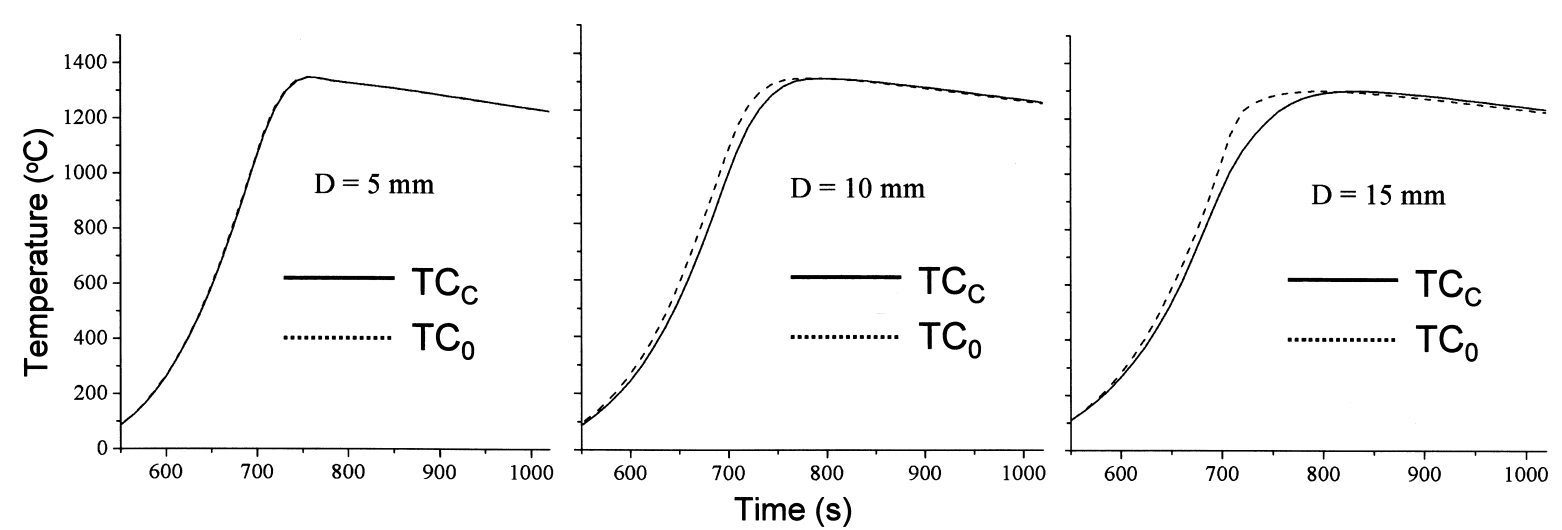

Fig. 12. Comparison of computed temperature profiles at the center, $\mathrm{TC}_{\mathrm{C}}$, and the surface, $\mathrm{TC}_{\mathrm{O}}$, of the pellets of 5 , 10 , $15 \mathrm{~mm}$ in size during sintering.

adding fine coke to the pellet, and a mesh generation method properly representing the contraction of bed height.

\section{Summary}

In the present paper, the feature of the structural change of the sintering bed was first outlined and a concept of the structural design of raw material bed, MEBIOS, was introduced. It has been proposed by "Research Project for Porous Meso-mosaic Texture Sinter" of ISIJ as a technology coping with the increasing the fine iron ores containing a large amount of combined water like marramamba. Further, previous results were reported on the "in situ" observation of the change in the structure of the sintering bed by using $\mathrm{X}$-ray CTS and on the numerical simulation.

Since a sintering process is characterized by the increases in the sizes of the cluster and void, it can be macroscopically regarded as a phenomenon that the macroscopic inhomogeneity of bed structure increases continuously. Hence, detour of the gas flow path through the bed becomes significant corresponding to the increases in the characteristic size of cluster/void. However, the detour of the gas flow path seems to be easy for an impermeable bed with around $30 \mathrm{~mm}$ size or less and it will not cause inhomogeneous sintering.

In the MEBIOS process, relatively large pre-granulated pellets (aging beds) smaller than about $15 \mathrm{~mm}$ in size are used and arranged in the sintering bed (induction bed). It was confirmed by X-ray CTS observation that unsintered part did not form just under the pellet. Additionally, promotion of gas flow attributed to a wall effect at the vicinity of the pellet surface was suggested. It should be noted that this effect can be one of the essential process principles for high speed sintering. Further, the promotion effect of the carbon source addition to the pellet on its induration was found.

At the same time, an initial attempt was made to develop a numerical simulation model by applying the commercial CFD code. A series of the laboratory-scale sinter pot experiments was carried out to obtain parameters for the simulation. The gas flow near the pellet surface and the differences in the temperature profiles near the pellet center and surface, and the surrounding sintering bed (induction bed) can be represented by using the developed simulation model.

\section{REFERENCES}

1) E. Kasai, W. J. Rankin, R. R. Lovel and Y. Omori: ISIJ Int., 29 (1989), 635

2) Y. Hida, J. Okazaki, K. Nakamura, K. Uekawa and N. Kasai: Tetsuto-Hagané, 78 (1992), 1021.

3) T. Kawaguchi, Y. Hadano, T. Murai and Y. Kawaguchi: Tetsu-toHagané, 80 (1994), 270.

4) E. Kasai: CAMP-ISIJ, 15 (2002), 718.

5) E. Kasai and M. V. Ramos: ISIJ Int., 39 (1999), 396.

6) T. Akiyama, H. Ohta, R. Takahashi, Y. Waseda and J. Yagi: ISIJ Int., 32 (1992), 829 